\title{
PT1a Stage Finding
}

National Cancer Institute

\section{Source}

National Cancer Institute. pT1a Stage Finding. NCI Thesaurus. Code C48760.

A pathologic primary tumor TNM stage finding. The definition of pT 1a stage finding depends on the particular type of cancer that it refers to; for example, for breast cancer, PT 1a stage finding is defined as follows: cancer with tumor size more than $0.1 \mathrm{~cm}$, but not more than $0.5 \mathrm{~cm}$ in greatest dimension; for lung cancer, pT 1a stage finding is defined as follows: cancer with a tumor size of $2 \mathrm{~cm}$ or less in greatest dimension, surrounded by lung or visceral pleura and without bronchoscopic evidence of invasion more proximal than the lobar bronchus (i.e., not in the main bronchus). The uncommon superficial tumor of any size with its invasive component limited to the bronchial wall, which may extend proximal to the main bronchus, is also classified as T1a. (from AJCC 7th Ed.) 